\title{
Ancient DNA: A Window to the Past of Europe
}

\author{
Marie-France Deguilloux Fanny Mendisco \\ Equipe Anthropologie des Populations Passées et Présentes, Université Bordeaux 1, UMR 5199 PACEA, Talence, France
}

\section{Key Words}

Ancient DNA - Mitochondrial DNA - European populations .

Neolithic transition - Genetic continuity

\begin{abstract}
Objectives: The history of European populations is characterised by numerous migrations or demographic events that are likely to have had major impacts on the European gene pool patterns. This paper will focus on how ancient DNA (aDNA) data contribute to our understanding of past population dynamics in Europe. Methods: Technological challenges of the palaeogenetic approach will be discussed. With these limitations in mind, it will be shown that the acquisition of aDNA now permits a glimpse of how human genetic diversity has changed, spatially and temporally, in Europe, from the Palaeolithic through to the present day. $\boldsymbol{R e}$ sults: Although early modern human DNA sequences come only from rare exceptionally well-preserved specimens, genetic samples of a reasonable size are becoming available for the Mesolithic and the Neolithic periods, permitting a discussion of regional variation in the inferred mode of the spread of farming. Palaeogenetic data collected for ancient and more recent periods regularly demonstrate genetic discontinuity between past and present populations. Conclu-
\end{abstract}

sions: The results indicate that only large diachronic aDNA datasets from throughout Europe will permit researchers to reliably identify all demographic and evolutionary events that shaped the modern European gene pool.

(c) 2014 S. Karger AG, Basel

\section{Introduction}

The history of European populations is characterised by numerous migrations and demographic events that likely have had major impacts on the patterns of the European gene pool. Three notable events have been suggested as having profoundly affected the genetic diversity of Europeans:

- First, the initial colonisation of the continent by anatomically modern humans approximately 45,000 years ago [1]. The question of interbreeding of anatomically modern humans with archaic humans, a topic that is highly debated since the publication of the complete Neanderthal genome [2], will not be addressed in this paper.

- Second, the Last Glacial Maximum, which was accompanied by important changes in the distribution of the human populations, i.e. the retreat of most

\section{KARGER}

E-Mail karger@karger.com

www.karger.com/hhe
C 2014 S. Karger AG, Basel

0001-5652/14/0764-0121\$39.50/0
M.F. Deguilloux

Equipe Anthropologie des Populations Passées et Présentes Université Bordeaux 1, UMR 5199 PACEA

Avenue des Facultés, FR-33405 Talence Cedex (France)

E-Mail mf.deguilloux@pacea.u-bordeaux1.fr 
northern populations into different southern refugees, followed by the recolonisation of Northern Europe after the retreat of the ice sheets by $20,000-16,000$ years ago.

- Third, the spread of the Neolithic culture in Europe between 9,000 and 5,000 years ago. The transition from a food-collecting to a food-producing economy, the Neolithic transition, is associated with dramatic changes in the European archaeological records. This Neolithic transition has been widely studied and is traditionally considered to be the major demographic process in Europe [3, 4].

In the last 30 years, the gene pool of current European populations has been widely analysed to better understand the demographic history of these populations. As a result, specific components of the European gene pool have been directly linked to the different migratory events described above [see 5 for a review]. However, because of the complexity of population dynamics in Europe, the extent to which the present-day genetic pattern can be attributed to the key episodes previously presented is still unclear. For example, genetic studies have delivered numerous, but often conflicting, inferences on the impact of Neolithisation on the modern European gene pool [see 6 for a review]. Indeed, even if geneticists now agree that the Neolithic farmers participated in the construction of the European gene pool, the importance of this Neolithic contribution remains unclear, and it can vary from 20 to $70 \%$ according to the genetic markers analysed or the analytical methods used [see 7-10, for example]. This assessment can be easily explained by the fact that modernday genetic diversity provides only indirect evidence about the evolutionary history of past populations. The patterns observed in the current European gene pool are the outcome of Palaeolithic and Neolithic processes, overlaid with 4,000 years of further developments that have blurred the picture. This observation encouraged palaeogeneticists to contribute to the debate by directly comparing genes from the ancient inhabitants of Europe to their contemporary counterparts. The goal of this paper is to show how the acquisition of ancient DNA (aDNA) data at different dates and places across the continent now permits us to catch a glimpse of how human genetic diversity has changed both temporally and spatially in Europe. Offering valuable insights into the evolution of the European gene pool at key moments in history, palaeogenetic evidence plays a primary role in providing a deeper understanding of the European populations' evolution as well as raising new questions concerning populations' dynamics.

\section{aDNA and Methodological Limits}

Before presenting several key studies dealing with European populations' palaeogenetics, no one can evade the question of the limitations that are intrinsic to the field of aDNA. Indeed, studies using aDNA are plagued by a unique set of methodological problems, such as variable and temporally limited DNA survival, problems with sequence authenticity, and the representativeness of samples that yield reliable results $[11,12]$. The first limit concerns the ability to obtain authentic aDNA from archaeological specimens. The preservation of DNA molecules and then the success rate of studies vary importantly from one specimen to another and can be a function of various factors, including environmental parameters, burial circumstances, and storage conditions before and after excavation. In concert with the limited number of well-documented archaeological specimens available for analyses, this point automatically leads to a low representativeness of samples that can yield reliable results. There are still only a limited number of aDNA samples; for example, a total of 100 Neolithic farmers' and 14 Mesolithic huntergatherers' mitochondrial sequences have been obtained to date, and it is obvious that such samples will not permit the complete resolution of the debate surrounding Neolithisation processes [6]. However, even this small sample size begins to shed some light on these processes in some specific regions, as we will see, and the continuous improvement of the aDNA database will doubtlessly provide critical insight into this topic. In addition to the paucity of ancient samples, the geographical and temporal representativeness of samples can also be questioned. Finally, we must always keep in mind that aDNA studies deal with human remains originating from funerary structures that are intrinsically biased. This point will be specifically addressed at the end of the paper.

Due to the technical difficulties induced by the nature of minute and degraded aDNA and the consequent risk of contamination, the authentication of amplified sequences represents a major interest in the field [13]. This is especially true when dealing with human remains. The results are usually validated through the determination of potential contamination sources, the use of decontamination techniques, and through the application of 'criteria of authenticity' [14]. All information supporting sequence authenticity must then be systematically provided so that the scientific community can better evaluate and accept the proposed results [13].

We must also keep in mind that the genetic picture presented by the aDNA studies is currently based primarily 
on mitochondrial DNA (mtDNA) results. The mtDNA in ancient samples is better conserved than the nuclear genome because of its higher frequency in living cells. Studies of maternally inherited mtDNA allow inferences to be drawn for only one sex, and it is conceivable that analyses of the Y chromosome or nuclear markers would present different patterns. The majority of aDNA studies presented in this paper have been restricted to short fragments amplified from hypervariable region 1 (HVR-1) of the mitochondrial genome. However, the advent of second-generation sequencing has recently revolutionised the study of aDNA, enabling researchers to move from the study of a few short fragments of DNA into the so-called palaeogenomic era. The recent development of second-generation sequencing (or next-generation sequencing - NGS) technologies has greatly benefited the field of aDNA [see 15 for a review]. Notably, unlike classical PCR approaches that rely on targeted PCR amplification of aDNA molecules using primers, the NGS approach allows for massive sequencing of ancient DNA molecules without prior targeted amplification. As a consequence, the new approach permits access to shorter fragments and to a much larger fraction of endogenous aDNA than PCR does. Moreover, new techniques provide degradation arguments (including short fragment read length, nucleotide misincorporations, and an increased fraction of purines close to sequence reads termini) permitting to clearly distinguish between ancient endogenous degraded reads and modern intact contaminants [16]. Finally, the more recent development of true single molecule sequencing [17] will likely bring us into a new era of ancient genomics.

The achievement of the first ancient human nuclear genome, from an extinct Palaeo-Eskimo from Greenland [18], demonstrated the great power of past genomics in addressing past demographic history of now-extinct cultures as well as in dating migration events with high confidence. This study demonstrated that it was possible to sequence the genome of an ancient human to a level that allowed for SNPs and population analyses to be run. The next technical challenge was to extend such a sequencing approach to material outside the permafrost regions. Moreover, past genomics have also demonstrated that interpretations of migrations and populations' relationships relying on mtDNA only could be misleading [19], and that as such, palaeogenomics should be of great relevance to our current understanding of European records. During recent years, NGS has been applied to a few well-preserved samples, and this approach has provided novel important autosomal data from ancient European remains $[20,21]$.

Palaeogenetics of Europeans
Despite the numerous inherent problems that confront palaeogeneticists, this field provides a unique opportunity to determine to what extent later European populations retain the genetic legacy of earlier groups. We will review the main contributions of the field to the understanding of past European population dynamics in the next section.

\section{aDNA and the European Palaeolithic Gene Pool}

The determination of early modern human DNA sequences has been confined, until now, to exceptionally well-preserved specimens. The majority of aDNA sequences obtained to date are from sites in Kostenki in Russia and Dolni Vestonice in the Czech Republic and the cave of Paglicci in Italy. The NGS approach has provided the complete mitochondrial genome from a 30,000-year-old modern early human from the Kostenki site in Russia [22]. The characterisation of the U2 mitochondrial haplogroup confirmed that haplogroup $U$ has a deep coalescence and may thus be older than other mitochondrial haplogroups in Europe. Three Gravettian individuals were analysed from the Paglicci cave of Southern Italy, a site that has been dated to $23,000 \mathrm{BP}[23,24]$. In this case, the analysis of amplified fragments of the HVR-1 of the mitochondrial genome did not permit a complete resolution of the individuals' haplogroups. Complete mitochondrial genomes were reported for three Gravettian remains from Dolni Vestonice (dated at $21,000 \mathrm{BP}$ ) and confirmed the overwhelming presence of haplogroup U in Palaeolithic European specimens [25]. Finally, mitochondrial data have been obtained from several specimens from the Magdalenian period in Spain and in Germany, and these have demonstrated the occurrence of haplogroups $\mathrm{H}, \mathrm{U}$, and derivatives during this period [25-27].

As a consequence of the scarcity of human remains from that period and the inherent methodological difficulties of aDNA conservation, the Palaeolithic European genetic pool remains poorly understood. Although the data demonstrate the presence of $\mathrm{H}$ and $\mathrm{U}$ sub-haplogroups in the Palaeolithic European mitochondrial gene pool, they do not allow any estimates concerning group diversity or differentiation. It is actually impossible to test whether some genetic differentiation between human groups echoes the cultural diversity highlighted for the periods concerned. Likewise, no inferences can be drawn concerning demographic events and population dynamics during the Upper Palaeolithic period. The NGS 
approach will doubtless provide crucial information about this period in the future.

Finally, it is interesting to note that some specific mitochondrial haplogroups that have been proposed to coalesce during the Palaeolithic period after the analysis of extant Europeans [haplogroups HV, HV1, J, T, and I, for example; see 5,8 ] have not been detected yet among human remains from that period.

\section{aDNA and the European Mesolithic Gene Pool}

The picture concerning the Mesolithic period is actually becoming clearer. Despite the fact that the aDNA dataset for the Mesolithic hunter-gatherers predating the Neolithic expansion presently includes only 14 human remains (from Lithuania, Poland, Germany, and Spain), all point out striking mitochondrial haplogroup homogeneity. Indeed, a surprisingly high frequency of mtDNA lineage $U$ (approximately $80 \%$, represented by sub-haplogroups U4 and U5) was discovered, and most of the ancient huntergatherers were shown to share mtDNA types that are relatively rare in Europeans today [20, 21, 24, 26]. This haplogroup composition, which is very particular and clearly different from that found in extant European populations, lends support to the fact that modern populations cannot be the direct descendants of the pre-Neolithic groups. Moreover, the characterisation of a remarkable genetic uniformity and little phylogeographic structure for Mesolithic European communities suggests a common origin for all pre-Neolithic individuals. The picture drawn is in agreement with a population of highly mobile groups that may have exchanged goods and individuals continent-wide.

Very recently, the NGS approach has permitted the acquisition of autosomal DNA data from two exceptionally well-preserved 7,000-year-old Mesolithic individuals from a site in Northwestern Spain [La Braña; see 21]. The data show that both Braña individuals fall outside of the range of modern European genetic variation, including Iberians, but they may show genetic affinities with extant populations from Northern Europe. In addition to confirming a clear regional genetic discontinuity between Mesolithic groups and extant populations from the same region, these results may confirm a potential gene flow between distant hunter-gatherers' communities.

Interestingly, the most complete palaeogenetic results that have been published for late European hunter-gatherers concern Central and Northern Europe [26], a region where substantial data for Neolithic farmers have also been obtained from.

\section{aDNA and the European Neolithic Transition}

Neolithic 'revolutions' represent the origin of huge changes in lifestyles, social structures, ideologies, techniques, and land use [28]. The Neolithic transition has been widely studied and is traditionally considered to be the major demographic process having shaped the European gene pool. Archaeological evidence and radiocarbon records suggest that the spread of agriculture over Europe has been complex, with a succession of migration phases and local admixture $[3,4]$. The processes underlying the agricultural expansion have long been a topic of considerable debate. What originally was perceived as a simple dichotomy between demic versus cultural diffusion is now generally recognised as a more complex set of processes involving cultural and population dispersion as well as variable patterns of population admixture [29].

The genetic study of the individuals who lived during the Neolithic transition adds precious information to our understanding of the local Neolithisation processes. As a consequence, our paper will first focus on early, or pioneer, farmer groups. The study of mtDNA from early Neolithic human remains has mainly focused on two different regions: the Central European plain connected with the LBK (Linearbandkeramik) expansion route, and the Northern regions of Iberia linked with the Cardial Pottery culture. The first general assessment that can be proposed is that farmers appear to have introduced a new set of mitochondrial lineages into Western Europe. Indeed, the Mesolithic-Neolithic transition is characterised by substantial gene pool changes, with a significant reduction in the abundance of the $U$ haplogroups found in Mesolithic hunter-gatherers together with the sudden appearance of a dozen new haplogroups $(\mathrm{H}, \mathrm{HV}, \mathrm{I}, \mathrm{J}, \mathrm{J} 1, \mathrm{~K}$, $\mathrm{N} 1, \mathrm{~T}, \mathrm{~T} 2, \mathrm{~W}$, and X; fig. 1a). The genetic discontinuity observed between the pioneer farmer groups and the predecessor Mesolithic communities clearly favours the hypothesis that a substantial migration accompanied Neolithisation.

At present, the majority of aDNA studies concern early Neolithic communities from Northern and Central Europe. Relevant analyses have been conducted on human remains originating from Linear Pottery culture sites [or LBK; see 30,31]. This culture is associated with the onset of farming in the temperate regions of Europe around 5,500 BC. A total of 45 Neolithic skeletons from sites in Germany, Austria, and Hungary have yielded reliable HVR-1 sequences. The initial interpretations have focused primarily on the characterisation of a high frequen- 


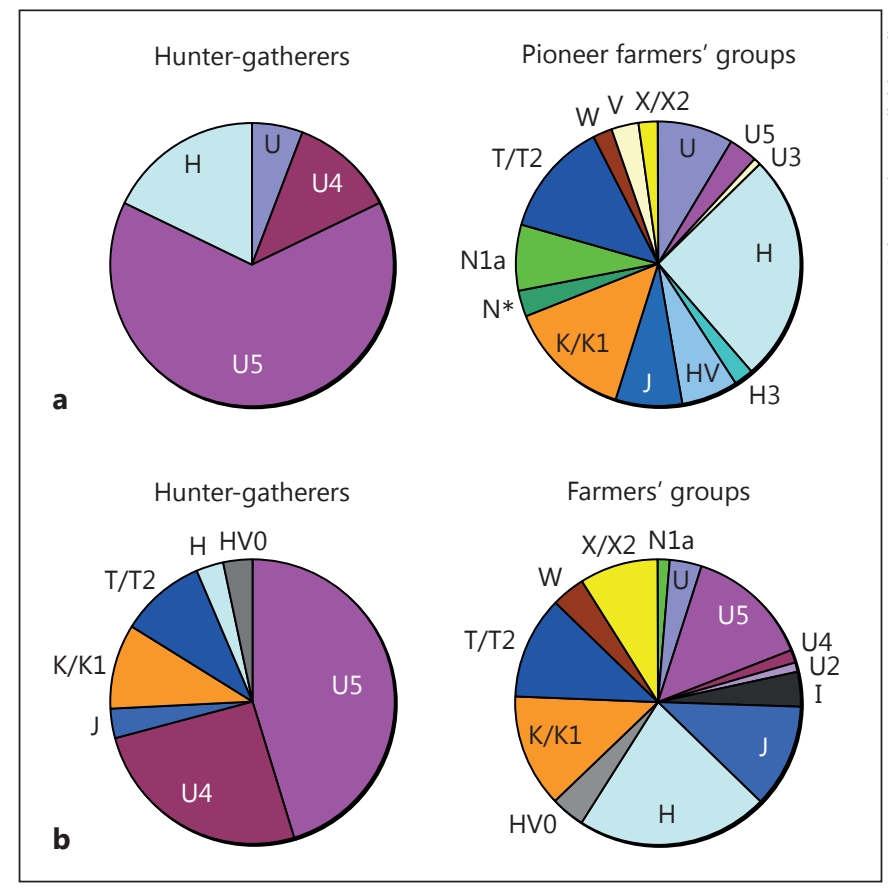

Fig. 1. Mitochondrial haplogroup composition of hunter-gatherer and farmer groups' gene pools: a before 4,500 BC and b after 4,500 BC.

cy of the mitochondrial N1a lineage in the LBK area. Because this lineage is exceedingly rare but widespread in Europe, the results lend support to the view that the first agriculturists had limited success in leaving a genetic mark on the female lineages of modern Europeans. A specific N1a haplotype described in an early Hungarian farmer was later characterised in a French megalithic burial chamber from the middle Neolithic period, raising questions concerning the possibility of lineage diffusion through farmer pioneer groups as far as Western France [32]. Genetic affinities among LBK groups and modernday Near-Eastern and Anatolian populations were also uncovered, supporting the hypothesis that there was major genetic input from this area during the advent of farming in Europe. However, extant regions from Central Europe were also shown to have mtDNA pools that were closely affiliated with the LBK population, lending support to the view that lineages characterised in LBK contexts originated from different sources, including the Near East and Eastern and Central Europe. Finally, the LBK population presented unique genetic features when compared to modern populations, confirming that major demographic events continued to take place in Europe after the early Neolithic period. A large-scale model pro-

Palaeogenetics of Europeans posed for the LBK expansion is one of demic diffusion with genetic input from the Near East into Central Europe. This large-scale demic diffusion model could be combined with a leapfrog colonisation model at the regional scale, which would explain (i) the relative speed of the LBK expansion in Central Europe, (ii) the clear genetic Near-Eastern connections seen in pioneer settlements, and (iii) a sizeable (but less important) input of Mesolithic populations to modern European genetic variation.

Important palaeogenetic results published several years later, describing late European hunter-gatherers from Central and Northern Europe, allowed the theory of an exogenous origin of the first Neolithic farmers to be tested directly. Bramanti et al. [26] obtained mtDNA sequences from 22 late European hunter-gatherer skeletons. The discontinuity between late hunter-gatherers, early farmers, and extant European populations from Central Europe provided persuasive evidence that the first farmers were not the descendants of local huntergatherers but immigrants who had come into Central Europe at the onset of the Neolithic transition. The results indicated that the migrating farmers, at least initially, did not mix significantly with the resident female huntergatherers.

Despite the fact that ancient Southwestern/Mediterranean biological data are typically underrepresented (mainly due to bone preservation issues), relevant palaeogenetic data have been recently reported for early Neolithic groups from Northeast and Northwest Iberia (for a total of 54 individuals). Samples of aDNA from early Neolithic settlers in Northeast Iberia have been obtained from sites dating back to the Cardial culture [33]. The Neolithic groups that have been analysed were characterised by a high frequency of haplogroups $\mathrm{Hg} \mathrm{N}^{*}$ and $\mathrm{X} 1$, and they showed a clear genetic discontinuity from modern populations. Bayesian coalescence-based simulations demonstrated that the results were compatible with a pioneer colonisation of Northeast Iberia at the early Neolithic period, characterised by the arrival of small genetically distinctive groups showing genetic connections with the Near East. Clear distinct gene pools were characterised for early Neolithic sites in the Cantabrian fringe of Iberia [including the absence of haplogroups $\mathrm{N}^{*}$ and $\mathrm{X} 1$; see 27], suggesting maritime colonisation by small and genetically differentiated Neolithic groups [34]. Finally, aDNA data obtained from several hunter-gatherers from the Northwestern region of Iberia confirmed a clear genetic discontinuity between hunter-gatherers and farming groups. 
In light of the information now emerging from palaeogenetic studies, it appears that genetic discontinuity between late hunter-gatherers, early Neolithic groups, and maternal contemporary counterparts is the rule. Phylogeographical arguments based on palaeogenetic data appear to support a model of leapfrog Neolithic migration in North-Central Europe and Northern Iberia [6].

Interestingly, all regions appear to have seen their early Neolithic gene pool modified by later evolutionary processes. Indeed, most of the studies performed to date on samples from the middle and late Neolithic periods show the disappearance of the haplogroups characteristic of pioneer farmers, suggesting that some genetic modifications could have taken place during the entire Neolithic period [35-38]. This point has been very recently confirmed by the analysis of a time transect spanning the $>3,500$ years of the Central European Neolithic period [from early to late Neolithic; 39]. Altogether, the findings demonstrate that the frequencies and the distribution of mitochondrial lineages brought by the first Neolithic farmers were highly modified during the Neolithic period (as well as later periods, as we will further describe).

To conclude, the increasing number of palaeogenetic data available for the pre-Neolithic and Neolithic periods provide crucial clues, including the following:

- There is a genetic break between late hunter-gatherers and early Neolithic communities, which points out substantial migration accompanying European Neolithisation.

- Genetic affinities between the early Neolithic populations and Near-Eastern modern-day populations were detected, suggesting a genetic input from the Near East during the Neolithic period. Nevertheless, this NearEastern input appears to have been subsequently remodelled through varying levels of interaction with local hunter-gatherers during the Neolithic expansion [31].

- The emerging pattern suggests heterogeneity among European Neolithic populations, with a clear regional variation in the lineages brought by farmer groups and varying relative biological contributions of indigenous Mesolithic hunter-gatherers across the continent.

- Palaeogenetic data for the middle or late Neolithic period suggest that migratory/demographic events would have later remodelled the groups' genetic pool throughout the Neolithic period, which could partially explain the observed discontinuity with extant Europeans (of course along with 4,000 years of further developments).

\section{aDNA and the Post-Neolithic Evolution of the European Gene Pool}

It appears that the genetic structure of European populations was not fixed in the Neolithic period; rather, it continued to be reshaped by subsequent demographic processes. Interesting palaeogenetic data have been obtained for more recent periods in a variety of regions (fig. 2). The majority of the studies note regional genetic discontinuity between ancient European and modernday populations. A compilation of 41 papers reporting palaeogenetic data for ancient European populations can be found in table 1 [20-27, 30-33, 35-38, 40-64]. It is worth noting that, among the studies discussing (dis)continuity between ancient and extant populations from the same region, $83.3 \%$ concluded genetic discontinuity, whereas $25 \%$ of the papers reported genetic continuity (two studies reported continuity with some extant groups and discontinuity with other groups). However, only a fraction of the studies used adequate statistical tests (37.5\%) or coalescence-based simulation (45.8\%), and these approaches are absolutely crucial to provide a persuasive quantitative argument of genetic (dis)continuity. Despite this shortcoming, as $92.3 \%$ of the studies that used such statistical/simulation approaches noted genetic discontinuity between extant Europeans and their ancient forbearers, we can conclude that a large majority of palaeogenetic studies highlight a genetic break between ancient and extant European populations.

\section{A Genetic Break with the Past}

On the whole, we have observed that the large majority of aDNA studies concluded that there is genetic discontinuity between ancient and extant Europeans. Various demographic and evolutionary mechanisms may have led to this genetic break with the past, including the strong likelihood of genetic contributions from migratory peoples that occurred during and after the Neolithic period. This gene flow may have been so significant that genetic signals from the earlier inhabitants of Europe were all but obliterated. Founder effects, genetic drift and bottlenecks must also have had dramatic impacts. In addition, it remains unclear whether the mtDNA genome has undergone selective pressure [65]. If mitochondrial function and variability play a role in adaptive selection, natural selection may have changed the face of Europe over time, causing certain mitochondrial lineages to disappear, while others have come to dominate the genetic 
Fig. 2. A map of ancient European populations genetically analysed (for more information, see also table 1 ).

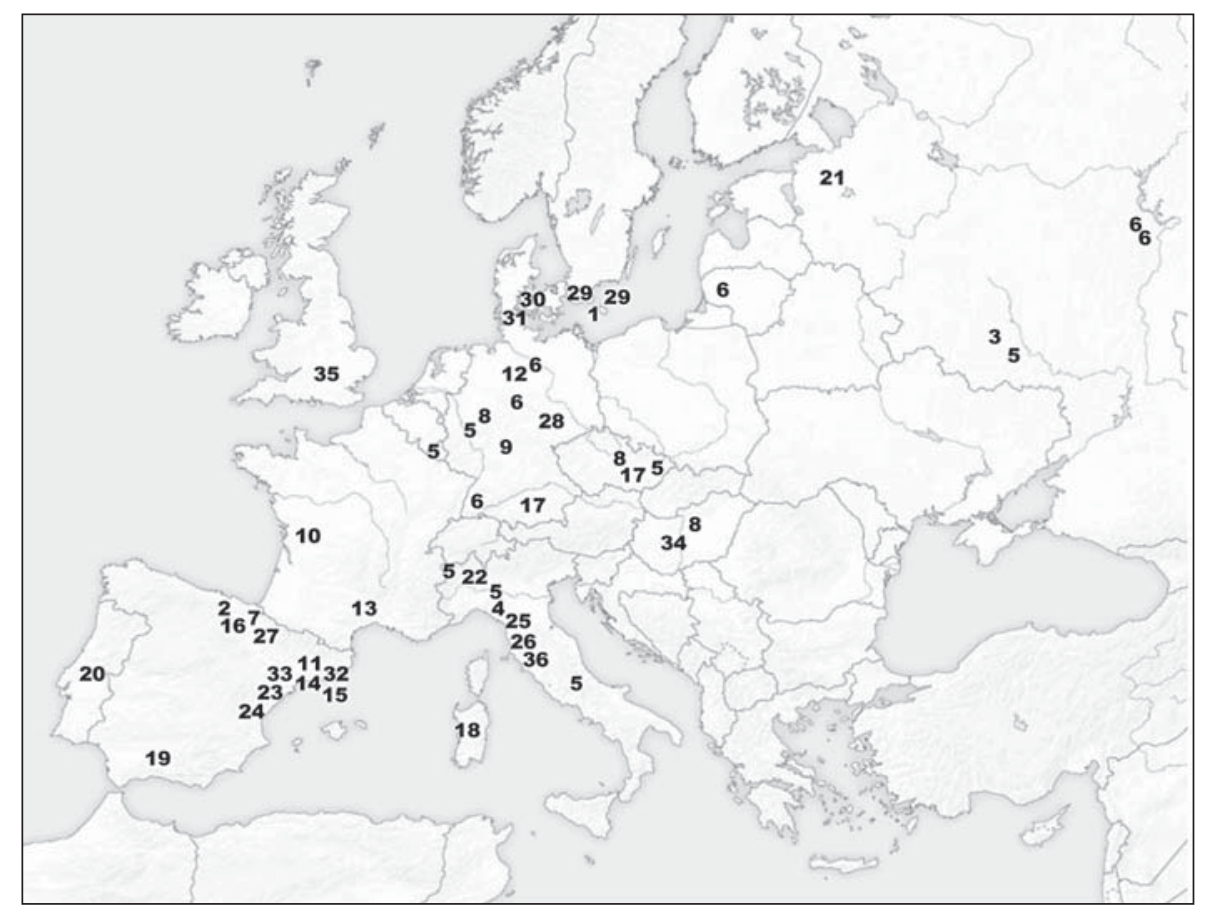

landscape. All of these events, either alone or in combination, have resulted in a general striking genetic discontinuity between past and present populations.

Finally, we believe that social parameters may also have played a significant role in lineage evolution, especially since the appearance of potentially hierarchic communities in the Neolithic period. As has already been mentioned, the ancient samples generally originate from funerary structures and may therefore not be representative of ancient populations as a whole. Indeed, putative selective mortality, cultural factors related to burial, environmental factors related to post-depositional processes, and methodological factors related to the excavation and analysis of skeletal samples could all potentially bias samples. We would like to particularly emphasise the impact of specific funeral practices on the representativeness of ancient samples. Funeral practices could include the selection of buried individuals according to their sex, their age, or their kinship. In the latter case, caution should be taken when making genetic diversity inferences from ancient funerary groups because an uncharacterised kinship can significantly bias allele frequencies. In addition, the study of late Neolithic sites has suggested exogamy and patrilocality [35-37], two practices that must have led to strong divergence between mitochondrial and $\mathrm{Y}$ diversities in ancient samples.

Palaeogenetics of Europeans
Funeral practices may also be driven by social criteria. We often do not know if the maternal lineages identified at different archaeological sites provide a snapshot of the whole population or only of a socially differentiated group. The question of social stratification has been posed for Etruscan groups, and palaeogenetic results may support the hypothesis of elite class extinction during an assimilation process [63]. The progressive disappearance of elite lineages through time has also been described in Hungary, where the rapid and comprehensive dilution of the haplogroups associated with the Magyar conquerors has been demonstrated [60]. The same question can even be posed for more remote periods, such as the Neolithic. For example, some authors have noted that only a small portion of the LBK population could have been interred in regular burials and that approximately $80 \%$ of the dead were treated in a way that hardly left any archaeological trace [66]. Burials, therefore, may represent a specific group of exceptionally treated people.

The question appears similarly important for middle Neolithic monumental funerary structures. For example, the extraordinary construction at Prissé (a 100-m-long mound constructed between 4,500 and 4,000 cal BC in West-Central France), compared with the very small number of individuals deposited in the chamber (8), supports the idea of selection and highlights discussions 


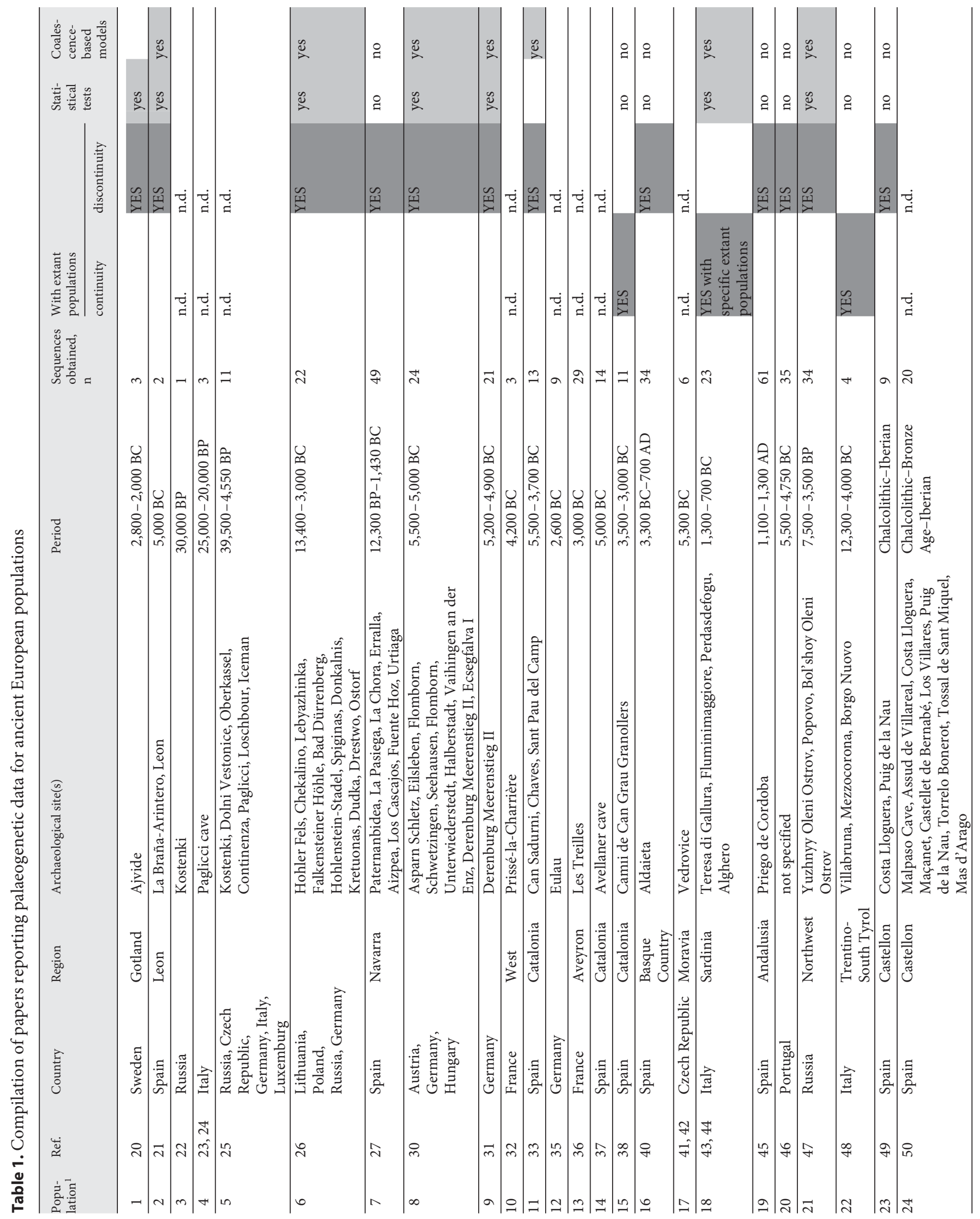




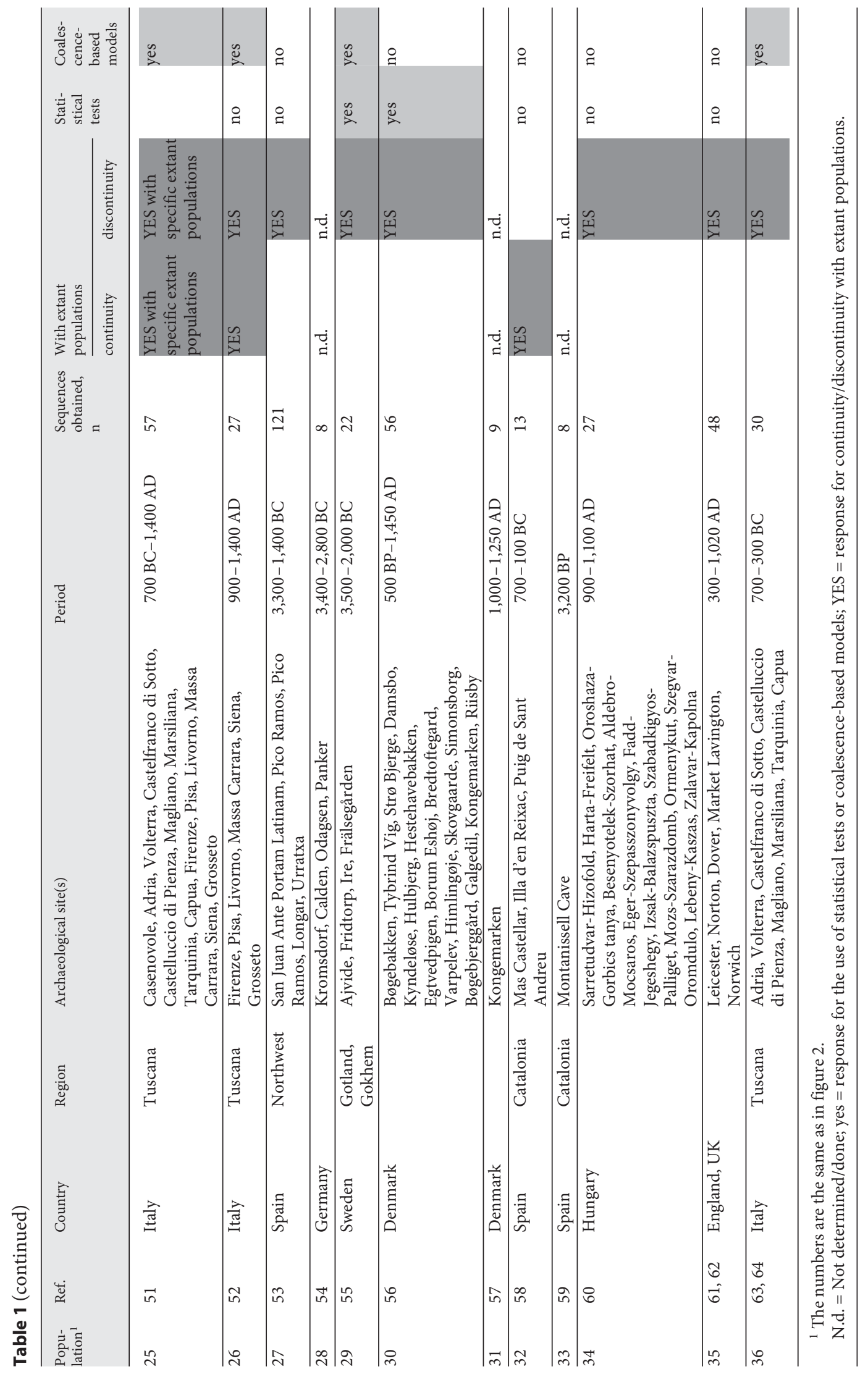


about the potential status of the deposited individuals [32]. It appears essential to discuss such social recruitment bias when interpreting palaeogenetic data.

Finally, cemeteries may have functioned over long periods of time and could therefore group together individuals corresponding to distinct biological groups or populations. A precise analysis of the human remains' dating must automatically accompany genetic analysis to verify group homogeneity at the site level. A recent study has proposed palaeogenetic data from human remains belonging to the Starčevo-Körös-Criş cultures [67]. Anthropologists and archaeologists specialising in this region later noted serious errors in the dating of the skeletons investigated, which significantly influenced the interpretation of the genetic data [68]. The conclusion of these specialists was that 'all efforts to produce authentic aDNA data are worthless if the archaeological background to a genetic project is missing or insufficiently explored' [68].

This conclusion can be applied to the aDNA field as a whole. It appears crucial that the genetic structure in ancient samples and the archaeological identity of individuals under study be systematically investigated within each archaeological site, and these data should be taken into account to propose reliable evolutionary scenarios for ancient European populations. This task necessitates a real interdisciplinary approach including archaeology and aDNA research. Only the increasing volume of palaeogenetic data, originating from various archaeological contexts, will permit to overcome the limitations linked to small sample size (more prone to the bias previously exposed).

\section{Conclusions}

Palaeogenetic data highlight the significant transformations that the genetic history of Europe has undergone and the resulting genetic discontinuity between modernday Europeans and their ancient forbearers. Migratory and demographic processes have mainly been inferred from patterns in modern mtDNA under the implicit assumption of genetic continuity among people dwelling in the same region during different time periods. Our paper notes that genealogical continuity between ancient and modern populations in the same area does not seem to be a safe general assumption but rather a hypothesis that, when possible, should be tested using aDNA analysis. On the whole, the aDNA approach has revealed additional levels of complexity in the population history of Europe- ans that were undiscovered from the study of only modern populations. Even if aDNA datasets are actually not sufficient to precisely reconstruct each prehistoric event that shaped the European gene pool, they do offer new perspectives on several aspects of the peopling of the continent.

All of these arguments justify broadening the sampling of aDNA in both time and space. The multiplication of aDNA studies should help to elucidate local demographic processes and to refine our knowledge of the migration patterns across the continent. Only many large diachronic aDNA datasets from throughout Europe will permit researchers to reliably identify all demographic and evolutionary events that shaped the modern European gene pool. Notably, future research should reveal the effects of post-Neolithic demographic processes because available data suggest that they had a major impact on the distribution of genetic variation. Such an increase in available aDNA data is also essential for the field to adopt a less qualitative approach, permitting more computational modelling, which should lead to a more precise identification of scenarios that can explain modern genetic data.

Finally, the palaeogenomic approach has clearly proved to be of high relevance in reconstructing human migrations and populations' relationships, potentially providing arguments contradicting with previous scenarios relying on mtDNA only. If the palaeogenomic approach has been applied so far to a few well-preserved European human samples, its next development will without any doubt be of great relevance to our understanding of the European records.

\section{Acknowledgements}

The authors kindly thank the organisers of the symposium 'Origins and Genetic diversity of Europeans' for the invitation to speak about European aDNA.

References

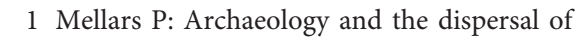
modern humans in Europe: deconstructing the 'Aurignacian'. Evol Anthropol 2006;15: 167-182.

2 Green RE, Krause J, Briggs A, et al: A draft sequence of the Neandertal genome. Sciences 2010;328:710-722.

3 Guilaine J: Premiers paysans du monde. Naissance des agricultures. Paris, Errance Press, 2000.
} 
-4 Bocquet-Appel JP, Naji S, Vander Linden M, Kozlowski JK: Detection of diffusion and contact zones of early farming in Europe from the space-time distribution of $14 \mathrm{C}$ dates. J Arch Sc 2009;36:807-820.

5 Soares P, Achilli A, Semino O, Davies W, Macauley V, Bandelt HJ, Torroni A, Richerds MB: The archaeogenetics of Europe. Curr Biol 2010;20:R174-R183.

-6 Deguilloux MF, Leahy R, Pemonge MH, Rottier S: European neolithization and ancient DNA: an assessment. Evol Anthropol 2012; 21:24-37.

7 Ammerman AJ, Cavalli-Sforza LL: The Neolithic Transition and the Genetics of Population in Europe. Princeton, Princeton University Press, 1984.

8 Richards M, Macaulay V, Hickey A, et al: Tracing European founder lineages in the Near Eastern mtDNA pool. Am J Hum Genet 2000;67:1251-1276.

9 Chikhi L, Nichols RA, Barbujani G, Beaumont MA: Y genetic data support the Neolithic demic diffusion model. Proc Natl Acad Sci USA 2002;99:11008-11013.

10 Semino O, Passarino G, Oefner PJ, et al: The genetic legacy of Paleolithic Homo sapiens sapiens in extant Europeans: a Y chromosome perspective. Science 2000;290:1155-1159.

$\checkmark 11$ Hofreiter M, Serre D, Poinar HN, Kuch M, Pääbo S: Ancient DNA. Nat Rev Gen 2001;2: 353-359.

-12 Pääbo S, Poinar H, Serre D, et al: Genetic analyses from ancient DNA. Ann Rev Gen 2004; 38:645-679.

-13 Gilbert MTP, Bandelt HJ, Hofreiter M, Barnes I: Assessing ancient DNA studies. Trends Ecol Evol 2005;20:541-544.

14 Poinar HN: The top 10 list: criteria of authenticity for DNA from ancient and forensic samples. International Congress Series 2003; 1239:575-579.

15 Hofreiter M: Palaeogenomics. C R Palevol 2008;7:113-124.

16 Overballe-Petersen S, Orlando L, Willerslev E: Next-generation sequencing offers new insights into DNA degradation. Trends Biotechnol 2012;30:364-368.

17 Orlando L, Ginolhac A, Raghavan M, et al: True single-molecule DNA sequencing of a Pleistocene horse bone. Genome Res 2011;21: 1705-1709.

18 Rasmussen M, Li Y, Lindgreen S, et al: Ancient human genome sequence of an extinct Palaeo-Eskimo. Nature 2010;463:757-762.

$\checkmark 19$ Rasmussen M, Guo X, Wang Y, et al: An Aboriginal Australian genome reveals separate human dispersals into Asia. Science 2011;334: 94-98.

20 Skoglund P, Malmström H, Raghavan M, Stora J, Hall P, Willerslev E, Gilbert MTP, Gotherström A, Jakobsson M: Origins and genetic legacy of Neolithic farmers and huntergatherers in Europe. Science 2012;336:466469.
21 Sanchez-Quinto F, Schroeder H, Ramirez O, et al: Genetic affinities of two 7,000-year-old Iberian hunter-gatherers. Curr Biol 2012;22: 1494-1499.

22 Krause J, Briggs AW, Kircher M, Maricic T, Zwyns N, Derevianko A, Pääbo S: A complete mtDNA genome of an early modern human from Kostenki, Russia. Curr Biol 2010;20: 231-236.

23 Caramelli D, Lalueza-Fox C, Vernesi C, et al: Evidence for a genetic discontinuity between Neandertals and 24,000-year-old anatomically modern Europeans. Proc Natl Acad Sci USA 2003;100:6593-6597.

24 Caramelli D, Milani L, Vai S, et al: A 28,000 years old Cro-Magnon mtDNA sequence differs from all potentially contaminating modern sequences. PLoS One 2008;3:e2700.

25 Fu Q, Mittnik A, Johnson PLF, et al: A revised timescale for human evolution based on ancient mitochondrial genomes. Curr Biol 2013; 23:553-559.

26 Bramanti B, Thomas MG, Haak W, et al: Genetic discontinuity between local huntergatherers and central Europe's first farmers. Science 2009;326:137-140.

27 Hervella M, Izagirre N, Alonso S, Fregel R, Alonso A, Cabrera VM, de la Rua C: Ancient DNA from hunter-gatherers and farmers groups from Northern Spain supports a random dispersion model for the Neolithic expansion into Europe. PLoS One 2012;7: e34417.

28 Cauvin J: The symbolic foundations of the Neolithic revolution in the Near East; in: Kuijt I (ed): Life in Neolithic Farming Communities. Boston, Kluwer Academic Publishers, 2000, pp 235-252.

29 Zvelebil M: The agricultural transition and the origins of Neolithic society in Europe. Documenta Praehistorica 2001;XXVIII:1-29.

30 Haak W, Forster P, Bramanti B, et al: Ancient DNA from the first European farmers in 7500-year-old Neolithic sites. Science 2005; 310:1016-1018.

31 Haak W, Balanovsky O, Sanchez JJ, et al: Ancient DNA from European early Neolithic farmers reveals their Near Eastern affinities. PLoS One 2010;8:e1000536.

32 Deguilloux MF, Soler L, Pemonge MH, Scarre C, Joussaume R, Laporte L: News from the west: ancient DNA from a French Megalithic burial chamber. Am J Phys Anthropol 2010; 144:108-118.

33 Gamba C, Fernández E, Tirado M, et al: Ancient DNA from an Early Neolithic Iberian population supports a pioneer colonization by first farmers. Mol Ecol 2011;21:45-56.

34 Zilhao J: Radiocarbon evidence for maritime pioneer colonization at the origins of farming in west Mediterranean Europe. Proc Natl Acad Sci USA 2001;98:14180-14185.
35 Haak W, Brandt G, de Jong HN, Meyer C, Ganslmeier R, Heyd V, Hawkesworth C, Pike AWG, Meller H, Alt KW: Ancient DNA, strontium isotopes, and osteological analyses shed light on social and kinship organization of the Later Stone Age. Proc Natl Acad Sci USA 2008; 105:18226-18231.

36 Lacan M, Keyser C, Ricaut FX, Brucato N, Duranthon F, Guilaine J, Crubézy E, Ludes B: Ancient DNA reveals male diffusion through the Neolithic Mediterranean route. Proc Natl Acad Sci USA 2011;108:9788-9791.

37 Lacan M, Keyser C, Ricaut FX, Brucato N, Tarrús J, Bosch A, Guilaine J, Crubézy E, Ludes B: Ancient DNA suggests the leading role played by men in the Neolithic dissemination. Proc Natl Acad Sci USA 2011;108: 18255-18259.

-38 Sampietro ML, Lao O, Caramelli D, Lari M, Pou R, Marti M, Bertranpetit J, Lalueza-Fox C: Paleogenetic evidence supports a dual model of Neolithic spreading into Europe. Proc Biol Sci 2007;2742:161-2167.

- 39 Brotherton P, Haak W, Templeton J, et al: Neolithic mitochondrial haplogroup $\mathrm{H}$ genomes and the genetic origins of Europeans. Nat Commun 2013;4:1764.

40 Alzualde A, Izagirre N, Alonso S, Alonso A, de la Rúa C: Temporal mitochondrial DNA variation in the Basque Country: influence of post-Neolithic events. Ann Hum Genet 2005; 69:665-679.

41 Bramanti B: Ancient DNA: genetic analysis of aDNA from sixteen skeletons of the Vedrovice. Anthropologie 2008;46:153-160

42 Zvelebil M, Pettitt P: Biosocial archaeology of the Early Neolithic: synthetic analyses of a human skeletal population from the LBK cemetery of Vedrovice, Czech Republic. J Anthropol Arch 2013;32:313-329.

43 Caramelli D, Vernesi C, Sanna S, et al: Genetic variation in prehistoric Sardinia. Hum Genet 2007;122:327-336.

44 Ghirotto S, Mona S, Benazzo A, Paparazzo F, Caramelli D, Barbujani G: Inferring genealogical processes from patterns of Bronze-Age and modern DNA variation in Sardinia. Mol Biol Evol 2010;27:875-886.

45 Casas MJ, Hagelberg E, Fregel R, Larruga JM, González AM: Human mitochondrial DNA diversity in an archaeological site in al-Andalus: genetic impact of migrations from North Africa in medieval Spain. Am J Phys Anthropol 2006; 131:539-551.

46 Chandler H, Sykes B, Zilhão J: Using ancient DNA to examine genetic continuity at the $\mathrm{Me}-$ solithic-Neolithic transition in Portugal, 2005; in Arias P, Ontañón R, García-Moncó C (eds): Actas del III Congreso del Neolítico en la Península Ibérica. Monographías del Instituto Internacional de Inverstigaciones Prehistóricas de Cantabria, Santander, 2005, pp 781-786.

-47 Der Sarkissian C, Balanovsky O, Brandt G, et al: ancient DNA reveals Prehistoric gene-flow from Siberia in the complex human population history of North East Europe. PLoS Genet 2013;9:e1003296. 
48 Di Benedetto G, Nasidze IS, Stenico M, Nigro L, Krings M, Lanzinger M, Vigilant L, Stoneking M, Pääbo S, Barbujani G: Mitochondrial DNA sequences in prehistoric human remains from the Alps. Eur J Hum Gen 2000;8: 669-677.

-49 Fernandez E, Oliver A, Turbon D, ArroyoPardo E: MtDNA analysis of ancient samples from Castellon (Spain): diachronic variation and genetic relationships. Interntional Congress Series 2006;1288:127-129.

50 Gamba C, Fernandez E, Oliver A, Tirado M, Baeza C, Lopez-Parra AM, Arroyo-Pardo E: Population genetics and DNA preservation in ancient human remains from Eastern Spain. Forensic Sci Int Genet 2008;1:462-464.

51 Ghirotto S, Tassi F, Fumagalli E, et al: Origins and evolution of the Etruscans' mtDNA. PLoS One 2013;8:e55519.

52 Guimaraes S, Ghirotto S, Benazzo A, et al: Genealogical discontinuities among Etruscan, Medieval and contemporary Tuscans. Mol Biol Evol 2009;26:2157-2166.

-53 Izagirre N, de la Rúa C: An mtDNA analysis in ancient Basque populations: implications for haplogroup $\mathrm{V}$ as a marker for a major paleolithic expansion from southwestern Europe. Am J Hum Gen 1999;65:199-207.

54 Lee EJ, Makarewicz C, Renneberg R, et al: Emerging pattern of the European Neolithic: perspectives from a late Neolithic Bell Beaker burial site in Germany. Am J Phys Anthropol 2012;148:571-579.
5 Malmström H, Gilbert MTP, Thomas MG, et al: Ancient DNA reveals lack of continuity between Neolithic hunter-gatherers and contemporary Scandinavians. Curr Biol 2009;19: 1758-1762.

56 Melchior L, Lynnerup N, Siegismund HR, Kivisild T, Dissing J: Genetic diversity among ancient Nordic populations. PLoS One 2010; 5:e11898.

57 Rudbeck L, Gilbert MTP, Willerslev E, Hansen AJ, Lynnerup N, Christensen T, Dissing J: mtDNA analysis of human remains from an early Danish Christian cemetery. Am J Phys Anthropol 2005;128:424-429.

58 Sampietro ML, Caramelli D, Lao O, Calafell F, Comas D, Lari M, Agustí B, Bertranpetit J, Lalueza-Fox C: The genetics of pre-Roman Iberian Peninsula: a mtDNA study of ancient Iberians. International Congress Series 2006; 1288:142-144.

59 Simon M, Jordana X, Armentano N, Santos C, Diaz N, Solorzano E, Lopez JB, Gonzalez-Ruiz M, Malgosa A: The presence of nuclear families in Prehistoric collective burials revisited: the Bronze Age burial of Montanissell Cave (Spain) in the light of aDNA. Am J Phys Anthropol 2011;146:406-413.

60 Tömöry G, Csanyi B, Bogacsi-Szabo E, et al: Comparison of maternal lineage and biogeographic analyses of ancient and modern Hungarian populations. Am J Phys Anthropol 2007;134:354-368.

-61 Töpf A, Gilbert MTP, Dumbacher JP, Hoelzel AR: Tracing the phylogeography of human populations in Britain based on 4th-11th century mtDNA genotypes. Mol Biol Evol 2006; 23:152-161.
62 Töpf AL, Gilbert MTP, Fleischer RC, Hoelzel AR: Ancient human mtDNA genotypes from England reveal lost variation over the last millennium. Biol Lett 2007;3:550-553.

63 Vernesi C, Caramelli D, Dupanloup I, et al: The Etruscans: a population-genetic study. Am J Hum Genet 2004;74:694-704.

64 Belle EMS, Ramakrishnan U, Mountain JL, Barbujani G: Serial coalescent simulations suggest a weak genealogical relationship between Etruscans and modern Tuscans. Proc Natl Acad Sci USA 2006;103:8012-8017.

65 Dowling DK, Friberg U, Lindell J: Evolutionary implications of non-neutral mitochondrial genetic variation. Trends Ecol Evol 2008;23: 546-554.

66 Nieszery N: Linearbandkeramische Gräberfelder in Bayern. Internationale Archäologie. Espelkamp, Verlag Marie Leidorf, 1995, vol 16.

67 Guba Z, Hadadi E, Major A, Furka T, Koos E, Nagy K, Zeke T: HVS-I polymorphism screening of ancient human mitochondrial DNA provides evidence for N9a discontinuity and East Asian haplogroups in the Neolithic Hungary. J Hum Genet 2011;56:784-796.

68 Banffy E, Brandt G, Alt KW: 'Early Neolithic' graves of the Carpatian Basin are in fact 6,000 years younger - appeal for a real interdisciplinary between archaeology and ancient DNA research. J Hum Genet 2012;57:467469. 